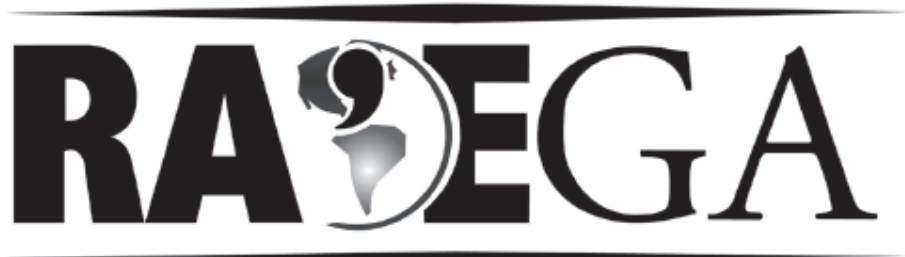

O ESPAÇO GEOGRÁFICO EM ANÁLISE

\title{
A REPRESENTAÇÃO DOS ASPECTOS SIMBOLICOS DAS FESTAS DE SANTOS REIS DE GOIÂNIA POR MEIO DE MAPAS MENTAIS
}

\section{REPRESENTATION OF SYMBOLIC ASPECTS OF THE SANTOS REIS'S PARTY OF THE GOIÂNIA THROUGH MENTAL MAPS}

\author{
Rosiane Dias Mota ${ }^{1}$ \\ Maria Geralda de Almeida ${ }^{2}$
}

\begin{abstract}
Resumo
O presente artigo consiste em uma reflexão sobre as representações das Folias de Reis formuladas por goianos. Os aspectos teórico-metodológicos utilizados no desenvolvimento deste têm como base, entre outras, às contribuições de Guarinello (2001) e Mariano (2009) com leituras sobre festa e cotidiano; e Kozel (2007) com a metodologia de leitura e interpretação de mapas mentais. Tem-se como procedimento teórico metodológico a revisão bibliográfica, a pesquisa de campo, e a leitura e interpretação dos mapas mentais. Apresenta-se como resultados uma análise das representações das
\end{abstract}

\footnotetext{
${ }^{1}$ Graduação em Tecnologia de Gestão Turística pelo Instituto Federal de Educação, Ciência e Tecnologia de Goiás. Especialista em Gestão de Empreendimentos Turísticos e Eventos, pela Faculdade Senac Goiás. Mestre em Geografia pelo Programa de Pós-graduação do Instituto de Estudos Sócio-ambientais Universidade Federal de Goiás. Doutoranda em Geografia pelo Programa de Pós-graduação do Instituto de Estudos Sócio-ambientais - Universidade Federal de Goiás (2012). Professora em Cursos Superiores e de Pós-graduação e Coordenadora Adjunta do Curso de Bacharelado em Administração Geral da Faculdade Lions. Goiânia, Goiás, Brasil. rosianeturismo@yahoo.com.br

2 Graduação em Geografia pela Universidade Federal de Minas Gerais, mestrado e doutorado em Geografia pela Université de Bordeaux III, pós doutorado em Geografia Humana pela Universidad de Barcelona, em Geografia Cultural pela Université Laval, Universita Degli Studi Di Genova e Universite de Paris IV Paris-Sorbonne. Professora colaboradora da Universidade Federal de Sergipe, professora Doutora Titular do Instituto de Estudos Sócioambientais da Universidade Federal de Goiás, Goiânia, Goiás, Brasil. mgdealmeida@gmail.com
} 
Folias de Reis para os goianos em ambientes e momentos externos a essas festas.

Palavras-Chave: Folia de Reis; Símbolos; Goiânia; Mapas Mentais.

\section{Abstract}

This paper is a reflection on the Folias de Reis' representations, formulated by goianos. Theoretical and methodological's aspects used in developing this article are based the contributions by Guarinello (2001) and Mariano (2009) with readings about party and everyday; Kozel (2007) with read's methology and interpretation by mental maps. It used methodological procedure literature review, field research, reading and interpreting maps. Present with results a analysis of the Folias de Reis' representations, formulated by goianos in external spaces and times outside these parties.

Keywords: Folia de Reis; Symbols; Goiânia; Mental Maps.

\section{Introdução}

O calendário festivo do Estado de Goiás possui várias festas culturais, a diversidade está relacionada tanto a eventos religiosos quanto a eventos cívicos e culturais. Acredita-se que a explicação para este amplo calendário está na sua forma de ocupação e formação sócio-espacial, e nas manifestações culturais de origens variadas que tem assumido diferentes dinâmicas ao longo dos anos. Tais manifestações se dividem em festas rurais, religiosas, urbanas entre outras que estão presentes em vários municípios do estado.

Dentre as Festas Religiosas existentes em Goiás destacam-se a as Folias de Reis. Consideradas por Brandão (1985, p.138) como "a viagem ritual mais difundida no Brasil e a mais rica de ritos e crenças próprias", as Folias de Reis tiveram seu início nas encenações das peças teatrais das Igrejas Católicas na Europa em meados do século XVI. Estas encenações relatavam passagens bíblicas e temáticas do ciclo natalino, incluindo a Epifania.

A "teatralização" da visita dos "Reis Magos" ao Menino Jesus contribuiu para a difusão do catolicismo tanto nos países europeus quanto nos colonizados, principalmente por Portugal, como é o caso do Brasil. De acordo com Rios (2006), quando trazidas para o Brasil durante a colonização, as 
Folias foram utilizadas pelos padres jesuítas para a catequização dos índios, uma forma de inserção e consolidação do catolicismo no continente.

No Brasil a festa de Reis progressivamente deixou o aglomerado urbano e tornou-se frequente no meio rural, e cada vez mais comum no interior do país. Após séculos, o intenso êxodo rural deslocou várias manifestações rurais para as cidades. Diante disso, entende-se que as Folias se iniciaram no "urbano", foram posteriormente para o "rural" e nas últimas décadas elas têm retornado ao "meio urbano" de forma ressignificada, distante da concepção inicial de Folias de Reis da colonização.

Ao migrar do campo para a cidade, as Folias encontraram um ambiente diferente do qual estavam habituadas. O novo espaço festivo possui uma dinâmica diferenciada em relação ao rural no que se refere ao calendário empregatício. No meio urbano as Companhias/Grupos de Folias Reis assumirem, portanto, uma dinâmica diferente da adotada no rural, mas sem deixar algumas características do mesmo. Na cidade de Goiânia as Festas de Reis compõem o processo adaptativo orientado pela "valorização" desta festa. O processo de valorização atinge tanto devotos quanto demais moradores da capital, contudo, estes interpretam a paisagem produzida pela folia de maneira diferente. Sob esse conhecimento o presente artigo tem como objetivo analisar as representações das Folias de Reis para os goianos em ambientes/momentos externos à essas festas. Para tal utiliza-se como aporte metodológico a proposta de leitura da representação por meio de mapas mentais apresentada por Kozel (2007).

A proposta teórico-metodológica da investigação apresentada no presente artigo é centrada na fenomenologia, corrente filosófica com a proposta do pesquisador realizar uma leitura dos fenômenos de forma a descrevê-los, compreende-los e interpretá-los até que se constitua a percepção do fenômeno. Neste caso, a percepção do fenômeno é obtida por meio da análise dos mapas mentais produzidos sobre as festas de folias. É necessário destacar a existência de um potencial expressivo sobre a manifestação investigada. 
O potencial expressivo, de acordo com Andreotti (2010)., é próprio, individual de cada sujeito. Neste caso, trata-se de uma carga cultural/de conhecimento adquirida anteriormente à leitura dos mapas. Este potencial foi obtido por meio de levantamento de dados sobre a manifestação como pesquisa bibliográfica e documental e "vivência" das festas de folias nos ciclos natalinos 2009/2010 e 2010/2011.

Para a presente investigação delimitou-se como sujeitos da pesquisa moradores de Goiânia e Região Metropolitana acima de 16 anos. Estes foram abordados/entrevistados fora do contexto festivo proporcionado pelas folias de reis, com o objetivo de compreender quais elementos simbólicos representam a festa para os mesmos. Em um universo de vinte pessoas entrevistadas, dez participavam, afirmaram conhecer ou receber Folias de Reis em suas residências na cidade de Goiânia e, os outros dez nunca tinham participado de festas ou "giros" de folias antes, e que conheciam apenas por meio de reportagens televisivas.

Junto aos sujeitos da pesquisa foi aplicado um roteiro de entrevista dividido em quatro partes. A primeira parte deste consistiu na identificação da pessoa, a segunda incidiu-se na produção, por parte do entrevistado, de um "desenho" (mapa mental) no qual ele responda a pergunta "O que é Folia de Reis para você?". A terceira parte constituiu-se de perguntas semiestruturadas que indicaram o sentido de pertencimento e reconhecimento do sujeito com a festa, e/ou com sua institucionalização. Na última parte do roteiro proposto o pesquisador apresentou quatro fotografias feitas durante as festas de reis "giros" e Encontro - de Goiânia, no ciclo natalino 2010/2011 e solicitou que o sujeito de pesquisa apontasse a foto que representaria, na concepção dele, a folia de reis, e com sua devida justificativa.

A última parte desse roteiro de entrevista foi determinada devido durante os "giros" de folias ser possível identificar aspectos distintos como as músicas (cantorias e instrumentos), a bandeira, a fartura de comida e o palhaço chamam a atenção dos participantes desta festa. Dessa forma escolheu-se fotos nestas temáticas para analisar qual constitui maior representação dessa festa para o entrevistado (Figuras 1, 2, 3 e 4). 


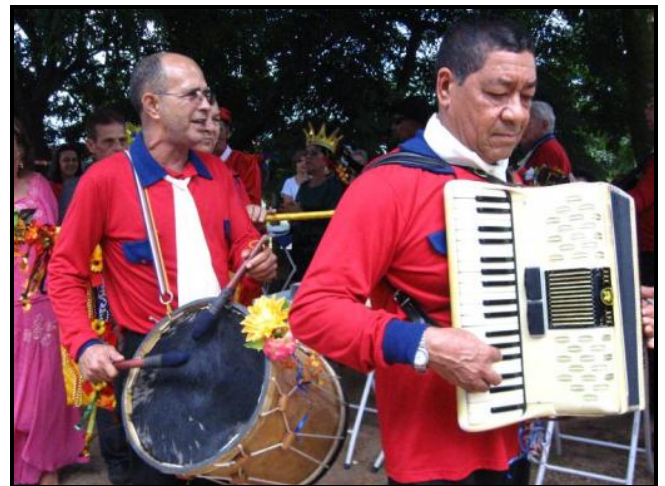

Figura 1 - Apresentação de Grupo de Folias em almoço na Associação de Idosos - St Aeroporto/Goiânia

Foto: MOTA, R.D. - Data: 13 jan 2010

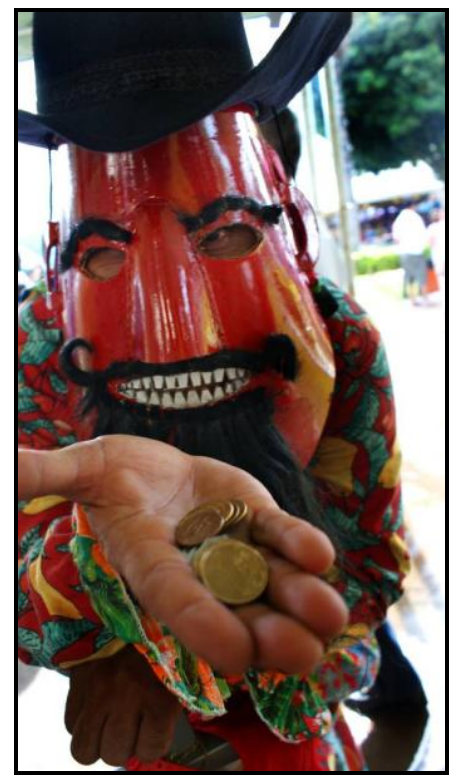

Figura 3 - Palhaço em Encontro de Folias/Goiânia

Foto: MOTA, R.D. - Data: 24 jan 2010

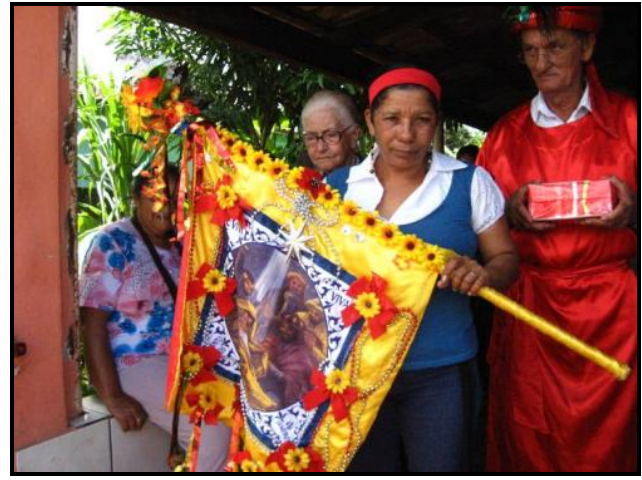

Figura 2 - Cantoria de Grupo de Folias durante festa de reis da Capela de Santos Reis na cidade de Trindade

Foto: MOTA, R.D. - Data: 10 jan 2010

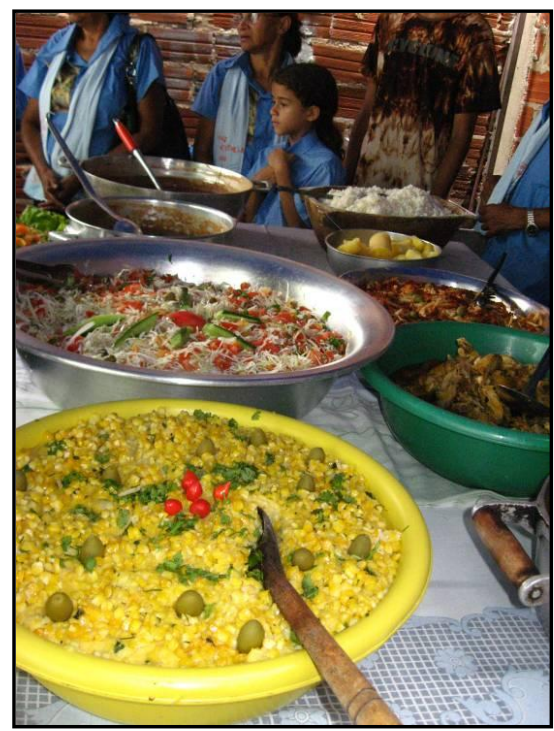

Figura 4 - Almoço em Pouso de Folia/Goiânia

Foto: MOTA, R.D. - Data: 28 dez 2009

No presente artigo, faz-se uma reflexão dos conceitos de cultura e festas, nesta destaca-se as festas de folias de reis, seu histórico e suas características. Apresenta-se ainda conceitos sobre as representações e mapas mentais, e detalha-se a aplicação da metodologia com os resultados obtidos, entre estes está a identificação dos elementos de maior importância para o sujeito nas Festas de Reis. 


\title{
Cultura e Festas: De folias em folias, de reis em reis em Goiânia.
}

Considera-se a cultura como uma manifestação popular e de heranças transmitidas, como destaca Claval (2001). As formas encontradas para a sua transmissão estão na reprodução e podem ocorrer por meio das festas, movimentos diferenciados da produção cotidiana da população local no espaço.

É nessa idéia de produção cotidiana que a concepção de festa se posiciona neste texto. As leituras realizadas sobre festas e festas de folias percorrem diferentes áreas do conhecimento, que ora se encontram e ora se separam. Guarinello (2001) conceitualiza a festa como:

\begin{abstract}
uma produção do cotidiano, uma ação coletiva, que se dá num tempo e lugar definido e especial, implicando a concentração de afetos e emoções em torno de um objeto que é celebrado e comemorado e cujo produto principal é a simbolização da unidade dos participantes na esfera de uma determinada identidade. Festa é um ponto de confluência das ações sociais cujo fim é a própria reunião ativa de seus participantes (2001, p.972).
\end{abstract}

As festas são, portanto, uma continuidade do cotidiano, estão ligadas a um "ciclo de reprodução da vida", como afirma Mariano (2009, p.3). Tal cotidiano sofre uma alteração no seu ritmo monótono por meio de uma organização, relacionada ao tempo-espaço, feita pelo próprio indivíduo, para "experienciar" o momento festivo de uma manifestação de origem tão distante.

Em Goiânia a festa de folias pode ser concebida como um exercício propício destas manifestações populares, nas quais se nota a forte presença das tradições de origem rural no meio urbano. Estas festas, que ocorrem no período de 25 de dezembro a 06 de janeiro, revelam na cultura urbana "traços" de identidade rural.

É comum nas festas rurais a decoração das casas com bandeirolas e folhagens de coqueiros. Para receber as folias rurais os donos das propriedades faziam grandes arcos com folhagens e flores naturais e/ou de papel; atualmente observa-se esse costume ainda nas folias da cidade de Goiânia (figuras 5 e 6 ). Esses "traços" da identidade contidos nas folias rurais se fazem presentes nas festas de Folias de Reis urbanas da capital. 


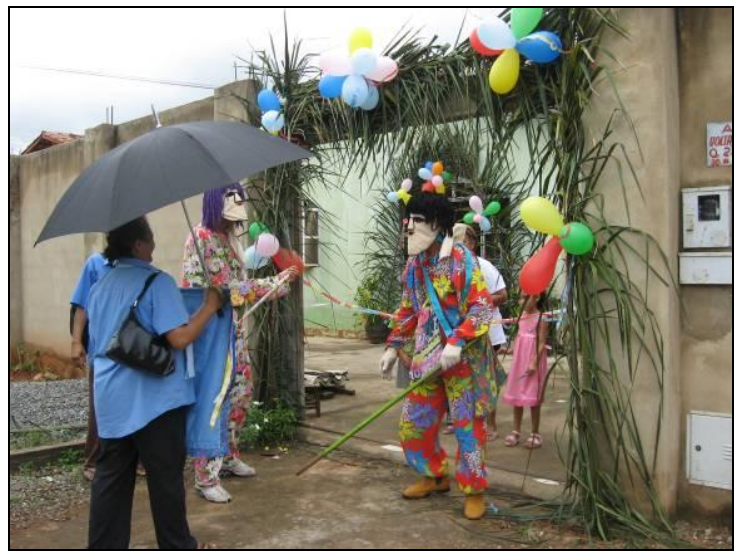

Figura 5 - Arco de folhagens na entrada de Pouso de Almoço de folias de reis Companhia de Reis Aroeiras/Goiânia Foto: MOTA, R.D. - data: 28/12/09

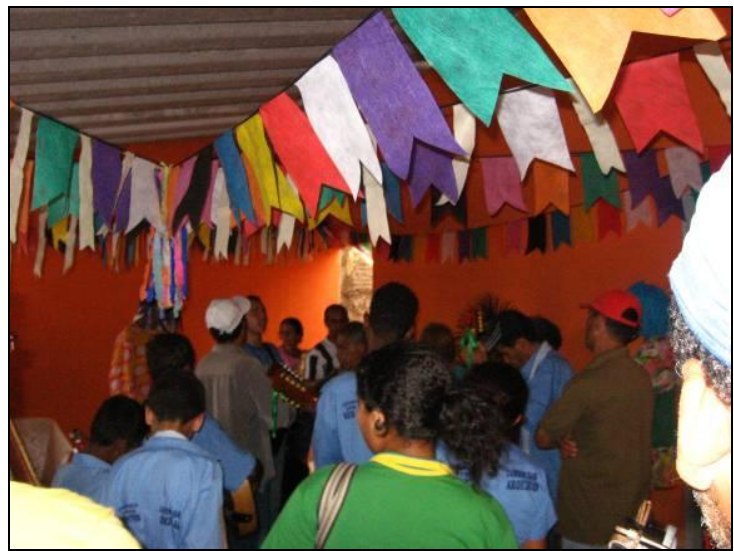

Figura 6 - Decoração com bandeirolas e fitas de crepom em Pouso de Almoço de folias de reis - Companhia de Reis Aroeiras/Goiânia Foto: MOTA, R.D. - data: 30/12/09

As festas são consideradas como um modo de reprodução de uma cultura. A cultura é, portanto, produzida pelas relações humanas e que a identidade é "construída" a partir desta. A cultura está em constante transformação. Nas Folias de Reis a cultura e a identidade se consolidam a partir das relações existentes entre os foliões, devotos, participantes dos "giros". A transmissão da cultura é feita por meio de diferentes linguagens, podem ser de maneira oral ou escrita, direta ou subjetivamente. Nesta linguagem as palavras - vocábulos - são substituídas por símbolos, imagens, valores, lembranças, entre outros. A leitura destes símbolos pode ser feita por meio da análise das representações e mapas mentais.

\section{Dos conceitos da Representação e dos Mapas Mentais}

A idéia de representação está ligada ao espaço vivido. Este é compreendido por Bonnemaison (2002) e Frémont (1980) sob o ponto de vista da experiência. Este tipo de espaço é formado, então, "pela soma dos lugares e trajetos que são usuais a um grupo ou indivíduo" (BONNEMAISON, 2002, p. 110). Neste espaço, em meio as relações sociais, ocorre o reconhecimento do indivíduo com as manifestações nele contidas. 
Nas festas a forma como as experiências são adquiridas, se vincula à proximidade do frequentador/participante com os organizadores e com a festa em si. Nas Festas de Folias de Reis, a "entrega", momento auge de todas as comemorações, proporciona experiências diferentes a cada pessoa que 0 assiste, são criadas representações individuais da festa.

Em uma reflexão sobre as representações espaciais verifica-se que "suas trajetórias [são] ligadas à percepção e representação provenientes de vivências, imaginários e significados construídos pelos seres humanos" (KOZEL \& SOUZA, 2009, p.123 - grifo nosso). As autoras compreendem a representação como uma "forma de linguagem", e por meio desta que se discutem as representações das Folias. Na linguagem elenca-se a não-verbal como aquela cujos sinais não são expressos por palavras ou por uma linguagem formalizada, mas que "vale-se de imagens sensoriais variadas, como as visuais, auditivas, cinestésicas (sic), olfativas e gustativas" (AGUIAR, 2004, p.25). A leitura das representações é feita através da apreensão das imagens sensoriais traçadas nos desenhos produzidos pelos entrevistados.

No que se refere a essa manifestação tem-se que, por meio das representações, "é possível entender a maneira pela qual as pessoas modelam as paisagens e nelas afirmam suas convicções e suas esperanças" (ALMEIDA, 2003a, p.71). Daí os sígnos são entendidos como uma forma de se compreender os valores - as representações - dos foliões e dos participantes das apresentações. Nas folias pode-se destacar a presença dos signos no rito, com as músicas e coreografias, que constitue-se em representações do sagrado durante o trajeto festivo.

A leitura da representação é feita por meio dos signos que são representados nos mapas mentais, e estes são "construções sígnicas [que] requerem uma interpretação/decodificação (KOZEL, 2006, p.115)", feita pelo investigador. A concepção de Cosgrove (1999) relativa à mapas está relacionada aos processos socioculturais, e estes são interligados a outros fatores e informações. Por meio da leitura da produção e mapas o autor uma metodologia de leitura das paisagens simbólicas produzidas. 


\section{Uma leitura, uma representação do que são as Folias de Reis}

Para a análise dos mapas adota-se a "metodologia Kozel" (2006, p133). Nesta o próprio sujeito produz o mapa por meio de um "desenho" que reflete o significado da manifestação para ele. Para tal, segue-se, portanto, os seguintes aspectos para interpretação do mapa:

1. Interpretação quanto à forma de representação dos elementos na imagem;

2. Interpretação quanto à distribuição dos elementos na imagem;

3. Interpretação quanto à especificidade dos ícones

a. Representação dos elementos da paisagem natural

b. Representação dos elementos da paisagem construída

c. Representação dos elementos móveis

d. Representação dos elementos humanos

4. Apresentação de outros aspectos ou particularidades

(KOZEL, 2006, p133)

Conforme apresentado anteriormente, a metodologia foi aplicada com vinte pessoas, nas quais realizou-se entrevistas semiestruturadas dividida em partes, acrescida do desenvolvimento de um mapa mental. É feita uma interpretação quanto à forma de representação dos elementos na imagem verifica-se a presença em todos os mapas de elementos/ícones próprios das festas de folias de reis (figura 7). A maioria destes símbolos remete as dimensões sagrada e profana da festa, assim como a importância da religiosidade impressa no rito para os foliões e para a continuidade desta tradição. 


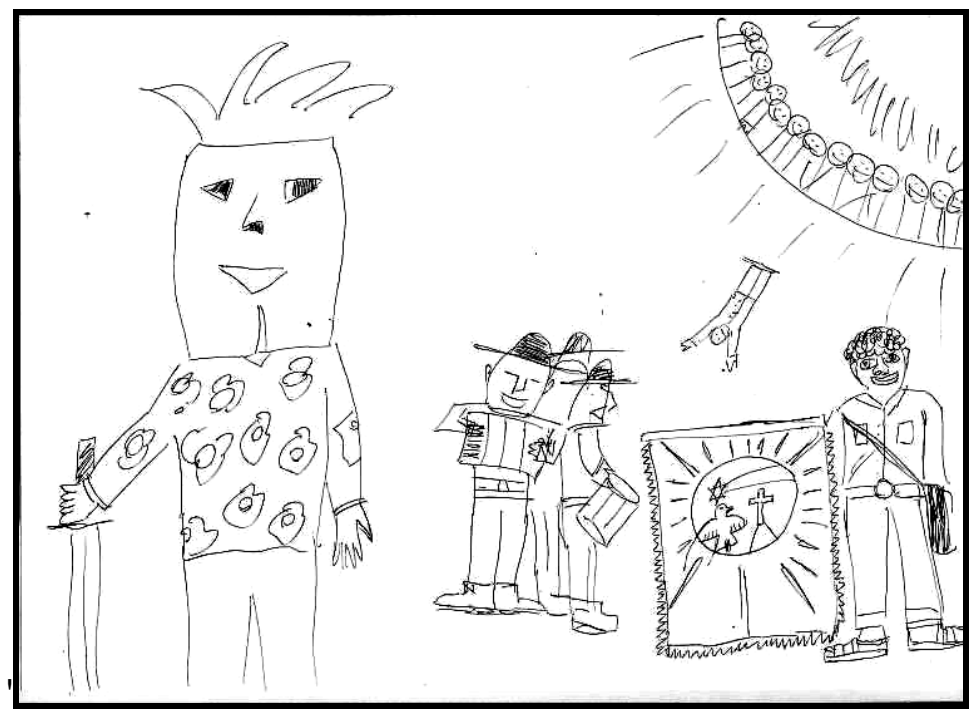

Figura 7 - Mapa mental - Elementos: Palhaço, músicos, alferes e bandeira. (masculino, 43 anos, folião)

A presença de letras apareceu em menor freqüência. $O$ sujeito utiliza a grafia com o objetivo de auxiliar o leitor a compreender a ideia transmitida por seu mapa, como descreve este sujeito "uma manifestação cultural, onde pessoas se vestem com roupas coloridas, visitam casas, tocam instrumentos, com melodias que me soam tristes, com letras toando(sic) santos da igreja católica" (Figura 8).

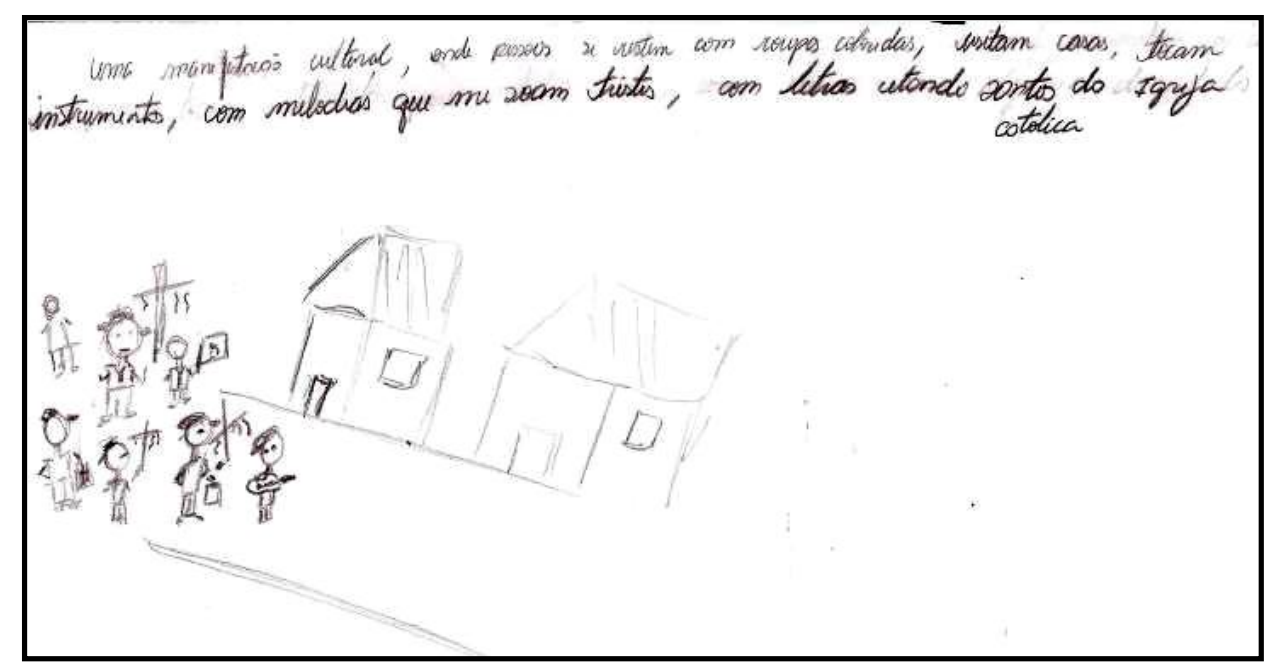

Figura 8 - Mapa mental - Letras/períodos escritos. (Feminino, 21 anos, conhece a festa)

Quanto à distribuição dos elementos na imagem, de acordo com Kozel \& Souza (2009, p.131), sua interpretação permite observar "como as formas 
estão dispostas na folha formando a imagem". Assim, os elementos podem estar dispersos, isolados, em formato geométrico, ou outros. Alguns mapas mentais aparecem dispersos, embora em formato de quadros (Figura 9). Esse formato se dá como se fosse um recorte da manifestação na paisagem cotidiana. Mesmo assim, esta festa não é desvinculada do cotidiano.

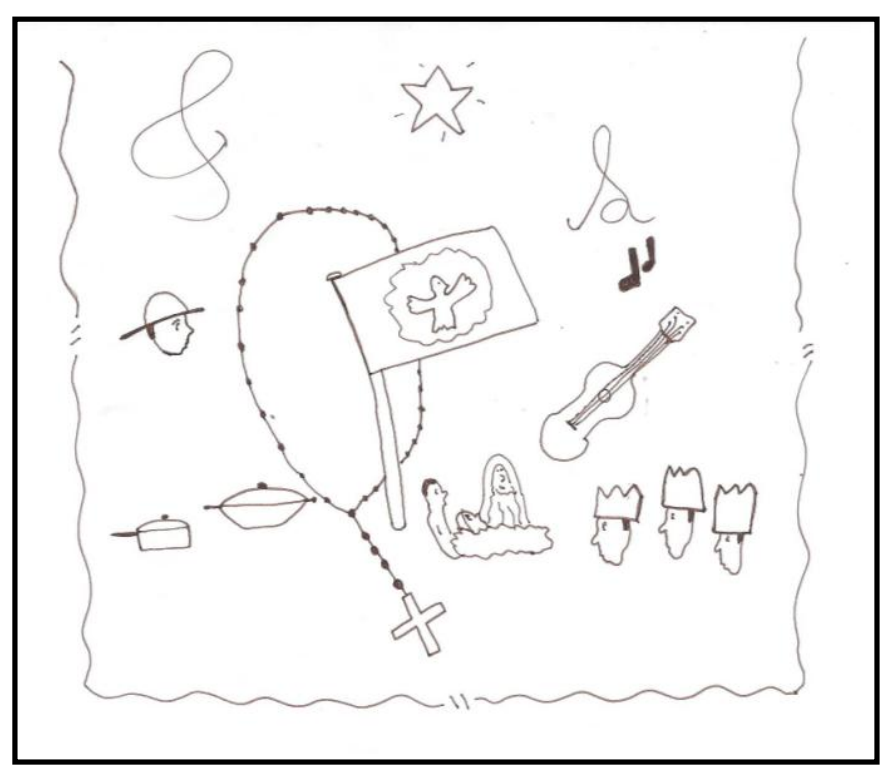

Figura 9 - Mapa mental - Distribuição Quadrilátera (Masculino, 24 anos, católico - não participa de grupos de folias).

Mas, em sua maioria, os mapas aparecem em formato horizontal. Acredita-se que isso se dá devido a manifestação se dispor em um cortejo e estar visualmente disposta nesse formato. Além disso sua mobilidade, cantorias de casa em casa, contribui para a fixação esta perspectiva (Figura 10). 


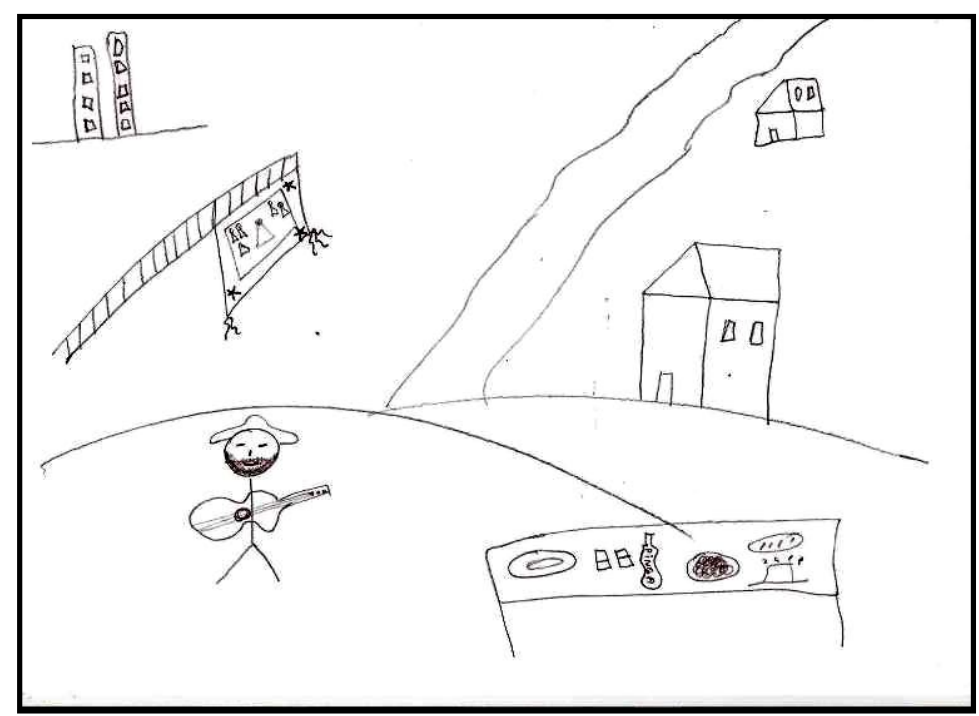

Figura 10 - Mapa mental - Distribuição horizontal (Feminino, 24 anos, já participou de festas de folias)

Quanto à interpretação relacionada à especificidade dos elementos da paisagem presentes nos mapas, esta pode considerá-los ligados à elementos naturais, elementos construídos, os móveis e os humanos. Na representação dos elementos da paisagem natural, aparece montanhas, sol, estrelas, lua, rios e animais, todos como um plano de fundo para a manifestação (Figura 11); na representação dos elementos da paisagem construída verifica-se que a maioria destes estão ligados à construções religiosas, como igrejas e cruzeiros, ou construções de vilarejos e pequenos agrupamentos rurais - casas de linhas simples, elementos terceiros que compõem a paisagem (Figura 12). $\mathrm{Na}$ perspectiva da disposição de casas a coletividade - agrupamento de pessoas, unidade - se faz presente.

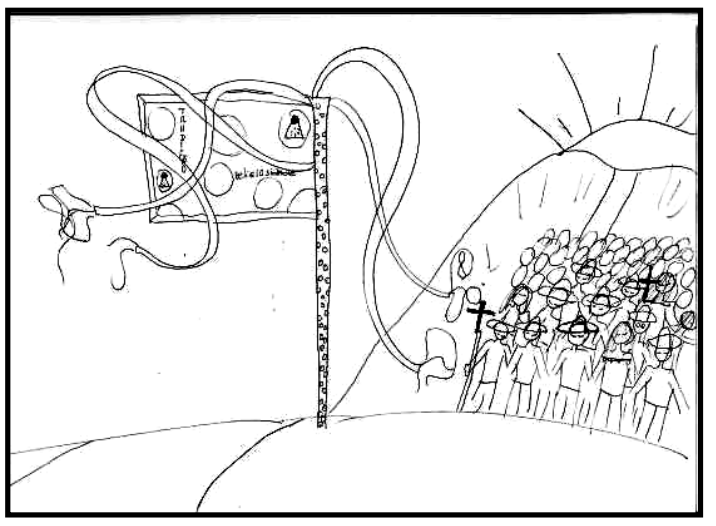

Figura 11 - Mapa mental - Representação dos elementos da paisagem natural (Feminino, 20 anos, participante das festas de folias).

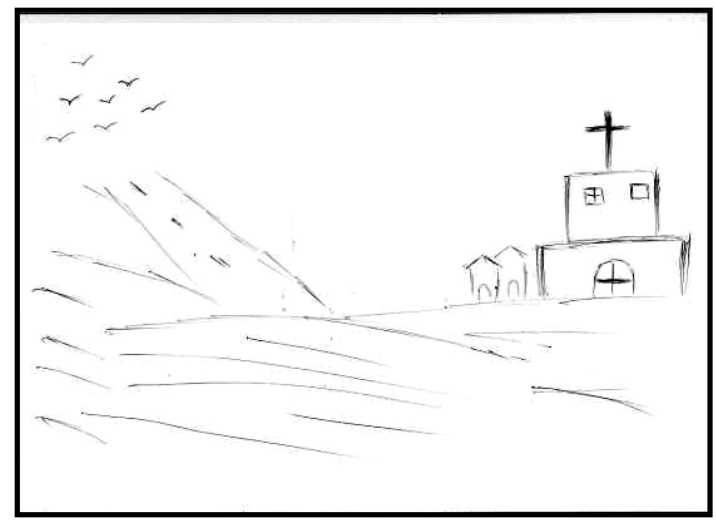

Figura 12 - Mapa mental - Distribuição horizontal (Masculino, 23 anos, participava das festas quando era criança). 
No que se refere à representação dos elementos móveis (Figura 13) veículos motorizados são totalmente ausentes. Estes dão lugar à percepção da festa em sua essência rural, ao apresentar animais como cavalos e carroças puxadas à tração animal utilizados para facilitar a mobilidade das pessoas nos mapas. Por último, a representação dos elementos humanos (Figura 14) está presente em $90 \%$ dos mapas. São representados devotos, foliões e pessoas a assistir as apresentações. Em todas as situações os elementos humanos foram colocados envolvidos no ritual da manifestação, ora com a bandeira, ora com instrumentos e em cantoria, ora em procissão.

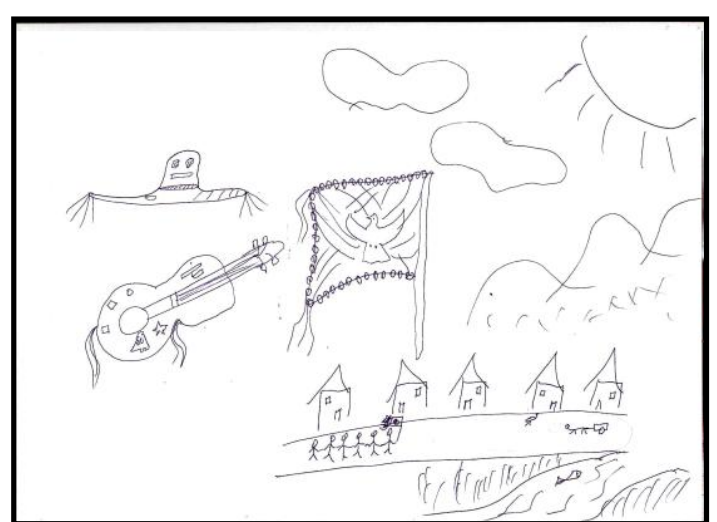

Figura 13 - Mapa mental - Representação dos elementos móveis. (Masculino, 29 anos, já participou de festas de folias).

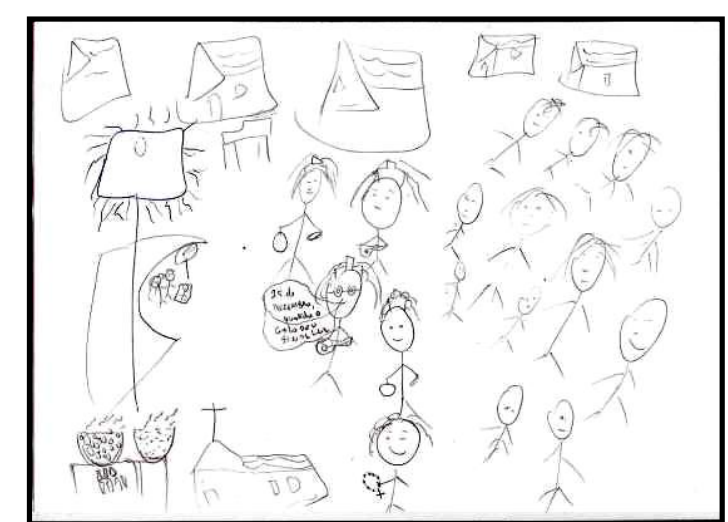

Figura 14 - Mapa mental - Representação dos elementos humanos (Masculino, 38 anos, já participou de festas de folias).

No item de apresentação de outros aspectos ou particularidades, realizase uma leitura interpretativa das imagens apresentadas pelos entrevistados. A figura da bandeira e/ou do presépio se faz presente na maioria dos mapas (Figuras 15 e 16). A representação do presépio consiste no nascimento do "salvador", questão que traz esperança de nova vida e de um mundo melhor. Para os foliões o presépio tem o mesmo significado, e demanda o mesmo respeito e devoção que bandeira. Esta possui o papel de "guia" do grupo, nela está retratado o presépio, e principalmente a representação dos "Três Reis Santos". 


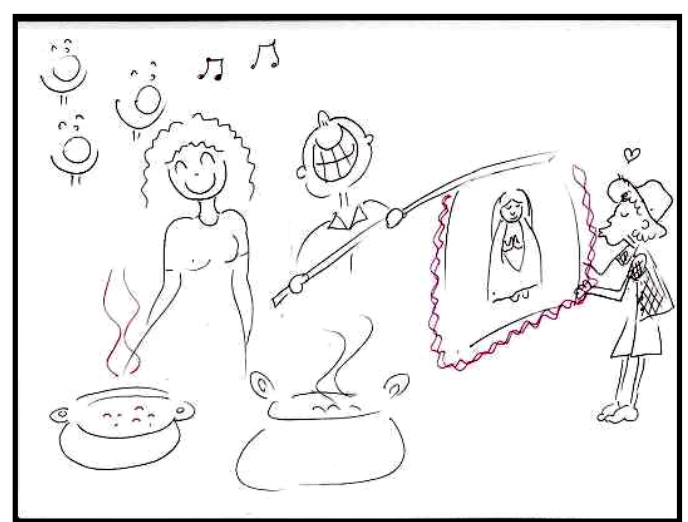

Figura 15 - Mapa mental - Fé, devoção à bandeira. (Feminino, 27 anos, participa de festas de folias).

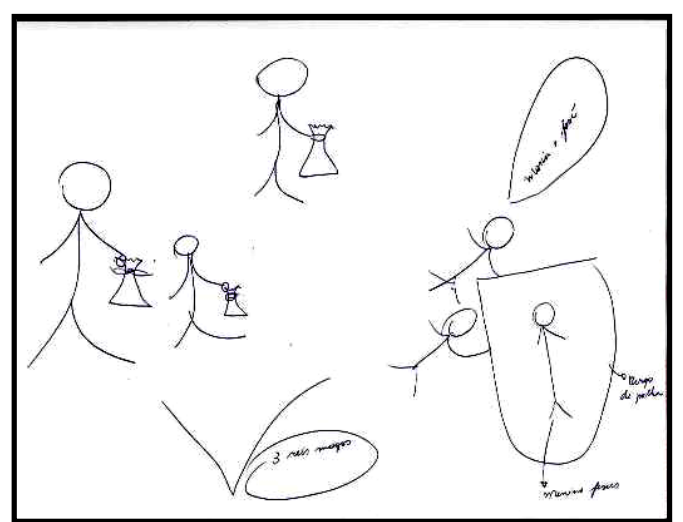

Figura 16 - Mapa mental - Fé, devoção ao Presépio. (Feminino, 26 anos, participou de festas de folias).

Durante a análise dos mapas mentais outros elementos foram identificados, entre eles estão a alimentação e a musicalidade (Figura 17 e 18).

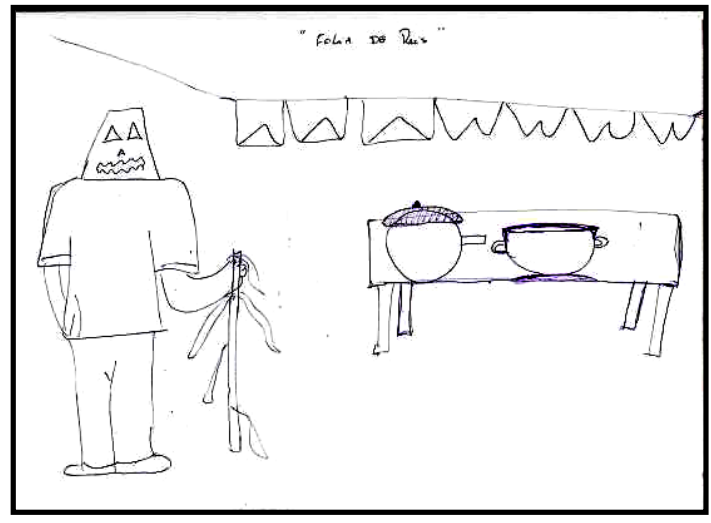

Figura 17 - Mapa mental - Comida (Feminino, 24 anos, tem a folia de reis como lembrança da infância)

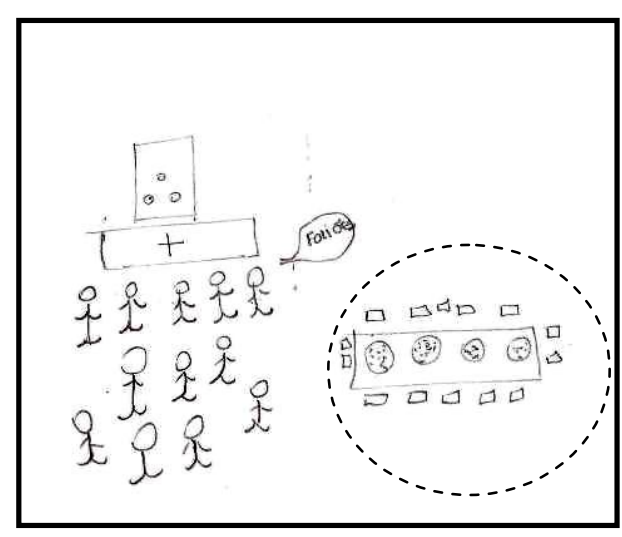

Figura 18 - Mapa mental - Comida e ritual do sagrado (Feminino, 24 anos, devota)

Esses elementos fazem parte dos "traços rurais" que estão na disposição de farta mesa com comidas tradicionalmente rurais como o queijo, pão de queijo e o requeijão no café da manhã; os bolos e biscoitos caseiros nos lanches; e a carne de porco, "carne de lata", almôndegas, galinhada, macarronadas, galinha caipira, feijão tropeiro servidos nos almoços e jantares nos "pousos de folias". O preparo desses alimentos em fornalhas, fogões a lenha ainda se faz presente em algumas casas, e se contrapõe com os fogões industriais (figura 19 e 20). 


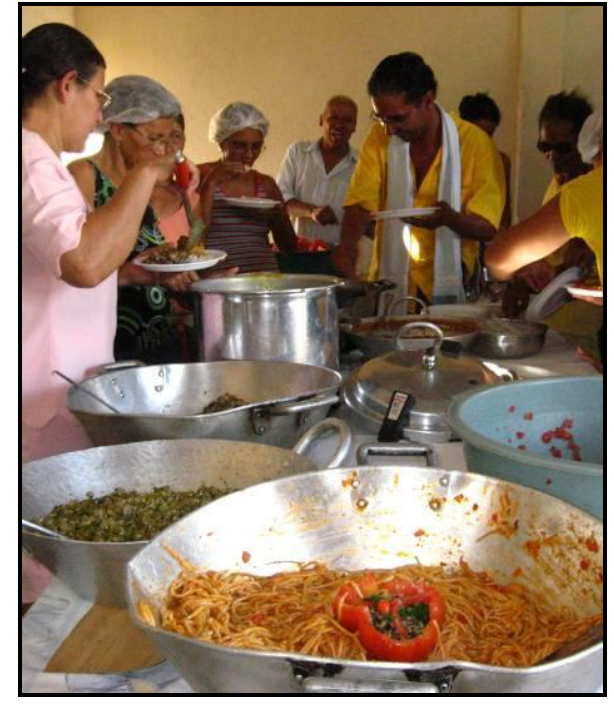

Figura 19 - Entrega de folias de reis Goiânia

Foto: MOTA, R.D. - data: 20/01/2010

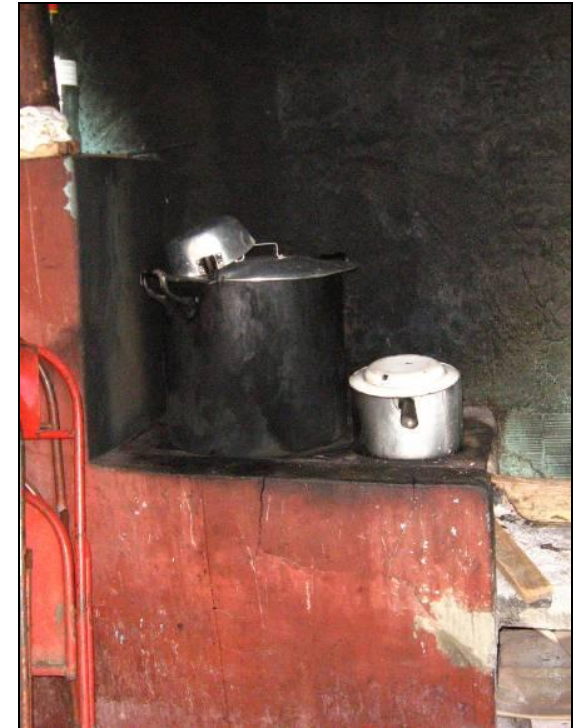

Figura 20 - Fornalha em Pouso de Jantar de folias de reis - Casa de folião no

Parque

Amazonas/Goiânia

Foto: MOTA, R.D. - data: 14/01/10

A não proximidade devocional, de alguns entrevistados, com as Folias de Reis, como já esperada, é retratada nos existência de elementos estranhos às festas do ciclo natalino, como fogueiras e bandeiras da festa do Divino Espírito Santo nos mapas mentais (Figura 21 e 22). Esse fato também é explicado ao comparar as respostas obtidas nas entrevistas na terceira parte do roteiro proposto.

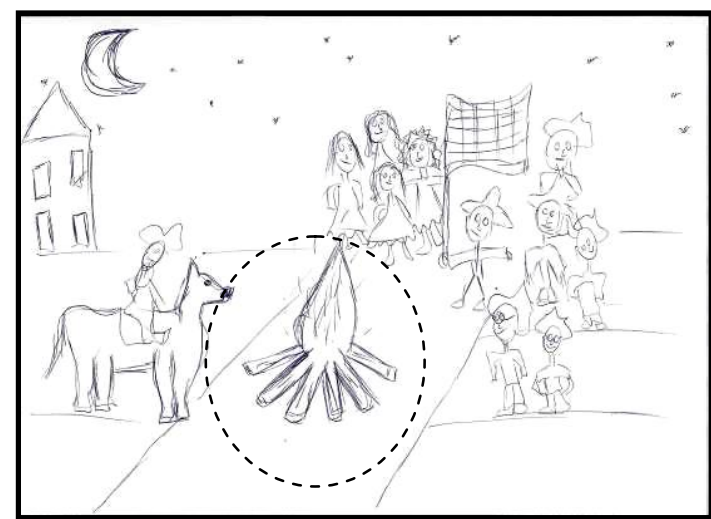

Figura 21 - Mapa mental - Fogueira: elemento próprio do ciclo junino (Feminino, 25 anos, nunca participou de uma festa de folias).

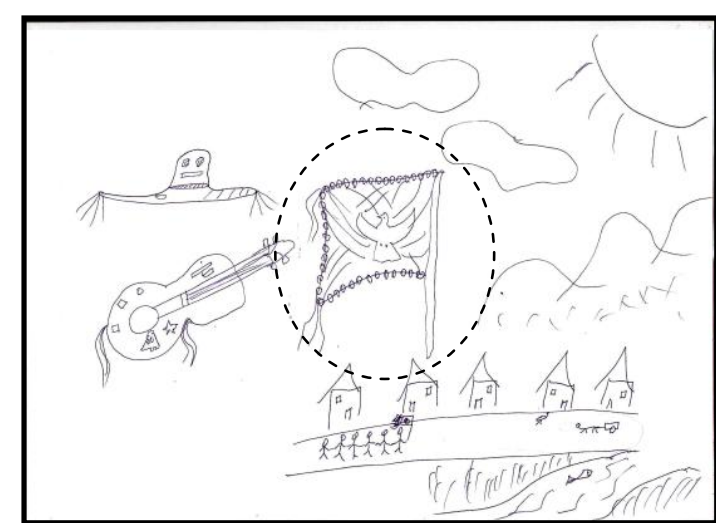

Figura 22 - Mapa mental - Bandeira do Divino Espírito Santo (Masculino, 29 anos, já participou de festas de folias). 
Nesta terceira parte foi possível concluir que a maioria dos entrevistados possui pouca proximidade com as festas de folias, e a representação destas para eles é vinculada diretamente à lembranças de festas de famílias, rurais, ou vivenciada com a vizinhança do bairro. A continuidade da manifestação foi destacada, pelos sujeitos da pesquisa. Mesmo diante desta reflexão, os mesmos afirmaram não receber grupos de folias de Reis em suas residências devido a fatores religiosos, ou ausência de oportunidade.

Apesar de não receber grupos em suas casas, aproximadamente $90 \%$ dos pontuaram que já participaram, assistiram, ou que possuem parentes foliões. Na pesquisa realizada por Mota (2011) alguns entrevistados, durante 0 Encontro de Folias de Goiânia em 2010, afirmaram que a festa de reis está ligada a pessoas que possuem "raízes rurais". A partir desta leitura verificou-se que todos os entrevistados na presente pesquisa possuem parentesco com pessoas moraram no meio rural, mas apenas $10 \%$ dos sujeitos afirmaram ter morado na roça.

Mesmo sendo moradores de Goiânia 99\% dos entrevistados afirmaram não saber onde estes grupos de folias "giram" na capital. Em algumas situações verificou-se que alguns destes entrevistados residiam em bairros existem grupos de folias, conforme comparação realizada com mapeamento apresentado por Mota (2011).

Ao investigar sobre o conhecimento em relação ao encontro de folias apenas dois entrevistados já haviam visitado, ou conheciam o evento, e emitiram uma reflexão negativa sobre o mesmo, enquanto tentativa de reprodução da cultura popular.

$\mathrm{Na}$ última parte do roteiro as fotos foram apresentadas e verificou-se que a maioria dos entrevistados afirmou que a foto com a bandeira era o símbolo de maior expressividade e mais importante da folia de reis. Seria a bandeira a representação da devoção, do santo adorado (Figura 23). 


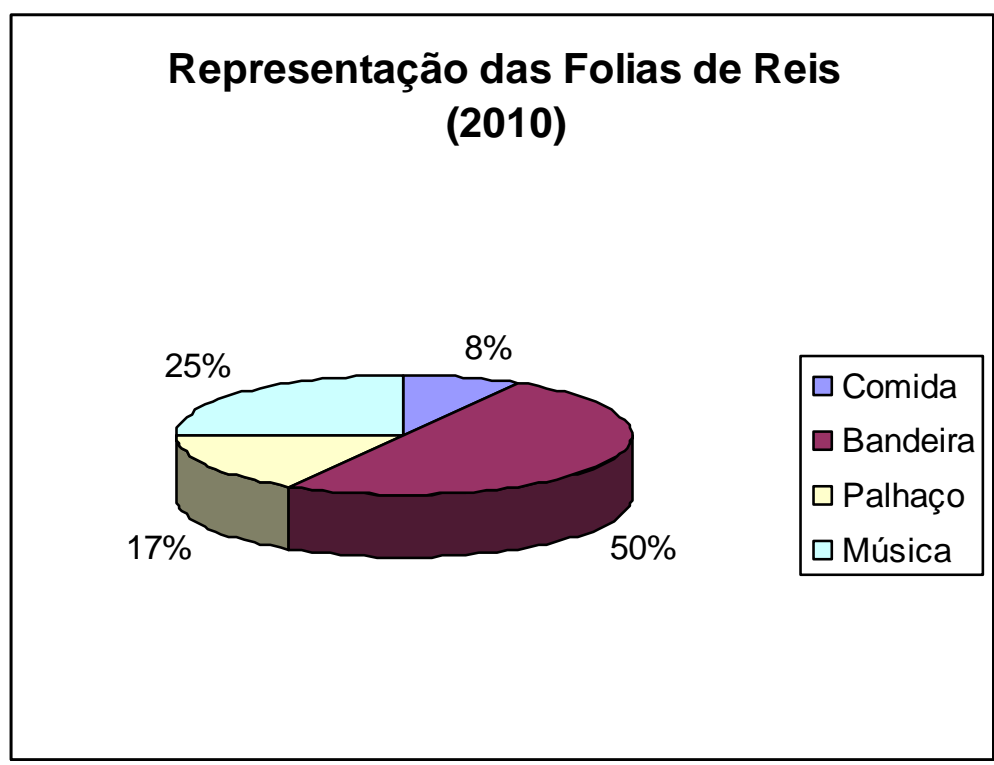
das fotos.

Figura 23 - Representatividade das Folias de Reis identificada por meio

Fonte: Resultados de entrevistas realizadas.

\section{Conclusão}

As Festas Religiosas, vistas sob a óptica do patrimônio imaterial, têm importante papel de perpetuação da cultura. O estudo das festas por meio da percepção constitui em ações investigativas, que faz emergir a importância destas manifestações culturais, como parte do simbolismo e da herança cultural de um povo e de sua identidade.

Neste âmbito, a identidade rural no meio urbano sobrevive a constantes modificações. As Folias de Reis, como prova de sobrevivência nessa realidade, vive inserida em cotidianas adaptações. Essa manifestação cultural faz parte da identidade da cultura goianiense e se faz viva em aproximadamente 25 grupos presentes em distintos bairros da capital.

Recorda-se, portanto, que a presente investigação teve como objetivo analisar as representações das Folias de Reis para os goianos em ambientes externos à essas festas. Os elementos de maior destaque foram aqueles ligados a devoção e aos rituais, como a bandeira, a cantoria, a devoção e a fé nos "Santos Reis". Como pode-se perceber, são várias as "marcas" impressas 
no espaço-tempo que configuram a representação das paisagens simbólicas produzidas pelas Folias de Reis para os sujeitos desta investigação.

Juntos, os aspectos inerentes à interpretação dos mapas mentais propostos pela "Metodologia Kozel", oportunizou o entendimento dos espaços festivos representados, e a percepção de quais elementos das festa de folias são considerados importantes para os entrevistados. Estes elementos são considerados signos advindos do espaço vivido e das leituras realizadas pelos sujeitos deste ensaio (KOZEL \& SOUZA, 2009).

O "potencial expressivo" apresentado anteriormente, desta forma, é evidenciado também nos sujeitos de pesquisa, tanto na situação em que os mesmos apresentam elementos presentes em outras festas e "giros" de folias de distintos ciclos festivos, quanto, estes retratam detalhadamente aspectos específicos desta festa do ciclo natalino e, esclarecem a configuração da manifestação em uma paisagem cultural espiritual.

\section{Referências}

AGUIAR, Vera Teixeira de. 0 verbal e o não verbal. São Paulo: UNESP, 2004.

ALMEIDA, Maria Geralda de. Em busca do poético do sertão. In: GEOGRAFIA: leituras culturais. ALMEIDA, M. G., RATTS, A. J. P. Goiânia: Alternativa, 2003 p.71-88.

ANDREOTTI, Giuliana. II senso etico ed estetico del paesaggio. In.: Ambiente, Società, Territorio: geografia nelle scuole. Rivista. n. 04/05, 2010. p.3-8. Disponível em:

http://www.aiig.it/Rivista/Numeri/2010/N04_05/04_05_contr_andreotti.pdf> Acesso em: 01 fev. 2011.

BRANDÃO, Carlos Rodrigues. Memória do sagrado: estudos de religião e ritual. São Paulo: Paulinas, 1985.

BONNEMAISON, Joel. Viagem em torno do território. In: CORREAA, Roberto L. e ROSENDAHL, Zeny (Org.). Geografia Cultural: um século (3). Rio de Janeiro: EdUERJ, 2002. p.83-131. 
COSGROVE, D. A geografia está em toda parte:cultura e simbolismo nas paisagens humanas. In: CORREA, Roberto Lobato, ROSENDAHL, Zeny. (Org.) Paisagem, Tempo e Cultura.2.ed. Rio de Janeiro: EdUERJ, 1999. p.92-123.

CLAVAL, P. A Geografia Cultural. Traduzido de Fugazolla Pimenta; Margareth de Castro Pimenta. 2.ed. Florianóplis: Ed da UFSC, 2001 p.60-70

FRÉMONT, Armand. As lições da ciências humanas. In: A região, Espaço vivido. Tradução de António Gonçalves. Coimbra: Livraria Almedina, 1980 p.17-28.

KOZEL, Salete; SOUZA, Lucileyde Feitosa. Parintins, que espaço é esse? Representação espacial sob a ótica do morador e do visitante. In: KOZEL, Salete; SILVA, Josué da Costa; FILIZOLA, Roberto; GIL FILHO, Sylvio Fausto. (Orgs). Expedição Amazônica: desvendando espaço e representações dos festejos em comunidades amazônicas "A festa do Boi-Bumbá: um ato de fé". Curitiba: SK Ed., 2009. p.117-144.

KOZEL, Salete. Mapas mentais - uma forma de linguagem: perspectivas metodológicas In: KOZEL, Salete; SILVA, Josué da Costa; GIL FILHO, Sylvio Fausto. (Orgs). Da percepção e cognição a representação: reconstruções teóricas da Geografia Cultural e Humanista. São Paulo: Terceira Margem; Curitiba: NEER, 2007. p.114-138.

GUARINELLO, Norberto Luiz Festa, trabalho e cotidiano. In. JANCSÓ, I \& KANTOR, I (orgs). Festa cultura e sociabilidade na América Portuguesa. São Paulo: Ed. Hucitec./Edusp, 2001. Volume II.

MARIANO, Neuza de Fátima. Tem Festa Caipira A Metrópole de São Paulo. In: XII ENCUENTRO DE GEÓGRAFOS DE AMÉRICA LATINA - EGAL, 2009, Montevideo. Anais... Uruguay, 2009. Disponível em: http://egal2009.easyplanners.info/area08/8239_Mariano_Neusa_de_Fatima.pdf Acesso em: 15 jun 10

MOTA, Rosiane Dias. "Senhor dono da casa, se não for muito custoso, vem abrir a vossa porta que nós viemos de pouso": as territorialidades produzidas pelos Grupos das Folias de Reis em Goiânia. 2011. $207 \mathrm{f}$. Dissertação (Mestrado em Geografia) - Orientadora: Profa Dra Maria Geralda de Almeida - Instituto de Estudos Sócio Ambientais, Universidade Federal de Goiás, Goiânia, 2011. 